\title{
(6) OPEN ACCESS \\ Not robots: children's perspectives on authenticity, moral agency and stimulant drug treatments
}

\author{
Ilina Singh
}

Department of Social Science, Health and Medicine, King's College London, London, UK

\section{Correspondence to} Dr llina Singh, Department of Social Science, Health and Medicine, King's College London, King's Building, Strand, London WC2R 2L, UK: i.a.singh@|se.ac.uk

Received 4 October 2011 Revised 4 May 2012 Accepted 5 June 2012 Published Online First 28 August 2012
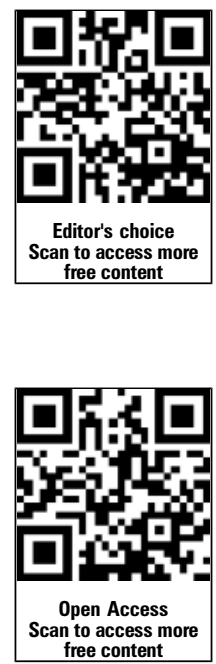

\section{SLinked}

- http://dx.doi.org/10.1136/ medethics-2012-100846

- http://dx.doi.org/10.1136/ medethics-2012-100879

- http://dx.doi.org/10.1136/ medethics-2012-100961

- http://dx.doi.org/10.1136/ medethics-2012-101283

To cite: Singh I. J Med Ethics 2013;39:359-366.

\section{ABSTRACT}

In this article, I examine children's reported experiences with stimulant drug treatments for attention deficit hyperactivity disorder in light of bioethical arguments about the potential threats of psychotropic drugs to authenticity and moral agency. Drawing on a study that involved over 150 families in the USA and the UK, I show that children are able to report threats to authenticity, but that the majority of children are not concerned with such threats. On balance, children report that stimulants improve their capacity for moral agency, and they associate this capacity with an ability to meet normative expectations. I argue that although under certain conditions stimulant drug treatment may increase the risk of a threat to authenticity, there are ways to minimise this risk and to maximise the benefits of stimulant drug treatment. Medical professionals in particular should help children to flourish with stimulant drug treatments, in good and in bad conditions.

\section{INTRODUCTION}

It is the attempted standardization of a human being and of a notion of achievement that is limiting, prescriptive and bullying ... Ritalin and other forms of enforcement and psychological policing are the contemporary equivalent of the old practice of tying up children's hands in bed, so they won't touch their genitals. The parent stupefies the child for the parent's good. ${ }^{1}$ Hanif Kureishi

Few topics generate such heated debate as the use of stimulant drugs in children. Stimulants, such as Ritalin or Adderall, are most frequently used as a treatment for attention deficit hyperactivity disorder (ADHD), a controversial condition characterised by symptoms of hyperactivity, impulsiveness and inattention. In some areas, diagnostic prevalence of ADHD is as high as $27 \%$ of school-age children; ${ }^{2}$ a more sober, but still controversial, estimate of worldwide prevalence of ADHD among children is $5 \% .^{3}$ Stimulant use for ADHD varies across and within countries ${ }^{4}$ and is growing most rapidly (at over $20 \%$ annually) in the developing world. $^{5}$

As popular author Hanif Kureishi's passionate protest against Ritalin illustrates, stimulant drug use in children is a vital node around which public concerns with children's liberties and childrearing practices are voiced. This protest is not new. Kureishi's article, published in the New York Times in February $2012,{ }^{1}$ echoes a sustained series of critical analyses of stimulant drug use in children, which began soon after Ritalin first came on the market in 1955. Writing a decade ago, the philosopher Frances Fukuyama agreed that Ritalin is a means of 'socially controlling children' and suggested that its use had significant implications for 'conventional understanding of identity and moral behaviour'. In 2003, the US President's Council on Bioethics raised similar concerns:

If the development of character depends on the effort to choose and act appropriately, often in face of resisting desires and impulses, then the more direct pharmacological approach bypasses a crucial element... By treating the restlessness of youth as a medical, rather than a moral, challenge, those resorting to behavior-modifying drugs might deprive that child of an essential part of this education. They might also encourage him to change his self-understanding, by coming to look upon himself as governed largely by chemical impulses and not by moral decisions grounded in some sense of what is right and appropriate (105-6). ${ }^{7}$

Such bioethical arguments about moral agency and authenticity overlap to some degree with a longstanding sociological critique of Ritalin. This critique has focused primarily on the medicalisation of undesirable social behaviours in children as part of an oppressive biopolitics, and the role of institutions (clinic, school, family, pharmaceutical industry) in creating a need and desire for pharmaceutical control of children's behaviour. ${ }^{8} 9$ An important common concern in different disciplinary analyses is that stimulants might suppress children's capacity to protest bad conditions, thereby allowing those conditions to prevail.

It is appropriate that the behavioural manipulation of young children by invasive means such as drugs continues to motivate public and intellectual debate. Arguments about children's liberties are particularly resonant at a time when scientific knowledge and tools are used ever more pervasively to shape behavioural, cognitive and emotional capacities across early developmental stages. ${ }^{10}{ }^{11}$ It is certainly plausible that such tools could undermine children's developing sense of self and their capacity for moral agency. Nevertheless, stimulant drug use continues to rise exponentially around the world, with little heed to passionate and persistent protests by public intellectuals and many others. We therefore need a balanced account of why, in spite of all the acknowledged concerns, stimulant drugs remain a compelling resource for children and families. To achieve such an account, we need to know what stimulant drugs are doing in the lives of children and families, and whether, and if so in what way, the ethical concerns about developing an authentic self and moral agency fit with children's daily experiences on the drugs. If we can better understand this fit, it should be possible to refine some of the relevant concepts, improve the arguments and ultimately move the debate along 
from where it has become stuck. It should also be possible to address an important practical concern: If there are broader cultural agendas at work in child development, how should we go about making good judgments about what is best for individual children?

In this article I use an empirical approach to evaluate the claim that stimulant drugs pose a threat to authenticity and to children's capacity for moral agency. Drawing on a study involving over 150 families in two countries, I show that children are able to report threats to authenticity related to stimulant drug treatments, but that the majority of children are not concerned with such threats. On balance, children report that stimulant drugs improve their capacity for moral agency, and they associate this capacity with an ability to meet normative expectations. I argue that although under certain conditions stimulant drug treatment may increase the risk of a threat to authenticity, there are ways to minimise this risk and to maximise the benefits of stimulant drug treatment. Medical professionals in particular should help children to flourish with stimulant drug treatments, in good and in bad conditions.

\section{On authenticity}

The concern-or the promise-that psychotropic drugs can transform a person is based on what some see as competing assumptions about what constitutes an 'authentic' self. Synthesising several different accounts of authenticity, Levy usefully analyses two views: the 'self-discovery view' and the 'selfcreation view'. ${ }^{12}$ On the self-discovery view, as described by Levy, authenticity means being true to oneself and listening to an 'inner voice' that all humans possess. In contrast, the selfcreation view sees authenticity as consisting of the effort to create oneself as one wishes to be. Bioethicists concerned about the use of psychotropic drugs in relation to authenticity tend to use the self-discovery view as a foundation for their arguments. The concern is that psychotropic drugs will 'alienate' persons from themselves and from the world as it really is. ${ }^{6}$ On the selfcreation view, however, psychotropic drugs can assist the project of authenticity, in so far as their use can help to remove the barriers that prevent persons from fashioning themselves as they wish to be. ${ }^{13} 14$

As Parens has noted, ${ }^{15}$ these two frameworks have more in common than is apparent on first view. Unless one believes in an essential, unchanging 'true' self, then both frameworks allow for mutually reinforcing processes of self-discovery and selfcreation on the path to authenticity. This view of authenticity as an iterative developmental process is an appropriate model for children, whose 'self-story' is still in the making. ${ }^{14}$ Moreover, as this article will show, the development of authenticity in children includes a process of socialisation, which informs both self-understanding and aspirations for the self.

Some might argue that if ADHD is a valid disorder, then there can be no question that stimulant drug treatment reveals a more authentic self, because illness itself is a form of selfalienation. Others might argue that the symptomatic behaviours of ADHD are part of the true self, and that medicating them away (and labelling them a pathology) denies a person the right to an authentic life. Both of these arguments hinge on the question of the reality of ADHD. However, even if it were possible to ascertain that an ADHD diagnosis refers to an objectively 'real' condition, it still would not necessarily follow that the use of stimulant drug treatments reveals a more authentic self. As several scholars have observed, ${ }^{13} 1617$ negative emotions and aberrant behaviours that characterise psychiatric conditions can be reasonable reactions, as well as clinically meaningful responses, to living in bad conditions. While these writers do not endorse individual suffering, they do raise an important question about the value of suffering and the consequences of treatment that may hinder the capacity to feel and to express suffering in certain contexts. Does treatment with psychotropic drugs, in quieting the response to, or awareness of, living in bad conditions, also threaten the capacity to protest those bad conditions? This is a serious concern that suggests a tension between individual and societal impacts of psychotropic drug treatments, as well as a tension between short-term and long-term harms and benefits of such treatments. Most important, this concern highlights the need for empirical investigations that analyse individual use of psychotropic drug treatments in relation to surrounding socio-political conditions.

\section{METHODS}

This article draws on data collected from the VOICES study (Voices On Identity, Childhood, Ethics and Stimulants). The study used a mixed-methods approach to examine the social and ethical implications of ADHD diagnosis and stimulant drug treatments, with particular attention to issues of moral agency, authenticity, stigma and personal responsibility. As part of the study, 151 children aged 9-14 were interviewed in the USA and the UK between 2008 and 2010. There were three groups in each country: children diagnosed with ADHD and taking stimulant medication; children diagnosed with ADHD and not medicated; and children without a psychiatric diagnosis. Diagnosed children were recruited from National Health Service (NHS) sites in the UK, and from university and community clinics in the USA. All child participants gave verbal and written assent and all parents gave verbal and written consent to participation. The study received NHS ethics approval in the UK, and Institutional Review Board (IRB) approvals in the USA. Consent was recorded on forms approved by the ethics committees. In all articles on the VOICES study, pseudonyms are used, and identifying details are sometimes changed to assure anonymity and confidentiality of participants and their families.

Parents filled out standardised measures as well as an open questionnaire. Memos were used to document conversations held with parents during the consent procedures and after children's interviews. Parent questionnaires were used to compare the severity of children's symptoms, as well as the quality and substance of the original clinical evaluation for ADHD. Overall, no significant differences were found among groups of diagnosed children; however, UK children scored higher than US children on the oppositional-defiant subscale of the Conners' Child Behavior Checklist.

Efforts were made to match children in both countries by broad demographic characteristics (age, gender, socio-economic status, as measured by the Hollingshead Four-Factor Index). The average child in the study is an 11-year-old white boy from a lower middle-class socio-economic background. We interviewed significantly more girls and ethnic minorities in the US than in the UK.

Interviews were first analysed thematically, using a coding frame developed in a coding team. Specific interview sections were subsequently reanalysed using methods appropriate to particular research questions, including discourse analysis and quantitative content analysis. Analytical comparisons rely on the concept of the 'ecological niche' rather than on national origin. ${ }^{18}$ The niche concept views the child in the context of individual, familial, social and national factors. These factors make up a network of proximal and distal, multi-directional influences in, on and from children. In the VOICES study, we 
identified two modal niches that children inhabited: a 'conduct niche' and a 'performance niche'. These modal niches are further described in the discussion below. ${ }^{19}$

\section{AUTHENTICITY AND STIMULANTS}

Accounts of experiences with stimulant drugs are an important contribution to bioethical thinking not least because of the unique dosing practices around these drugs. Sustained-release versions (Ritalin XR, Concerta and Adderall are the most prominent commercial brands) have an effect for a maximum of $8 \mathrm{~h}$; short-acting formulations are effective for 3-4 h. Between doses, children return to baseline functioning. Children may forget to take their medication on a given day; or, often with support of their parents, they skip doses, particularly at weekends and school holidays. The on-off rhythm of stimulant drug effects and the need to repeatedly justify stimulant drug doses support a degree of reflexive awareness in caregivers and in children themselves about the association between individual behaviour and drug effects. ${ }^{20}$ This reflexivity offers a unique opportunity for research on the perceived impacts of stimulant drugs.

In interviews, children were asked directly to discuss their views on whether or not the use of stimulants posed a threat to authenticity. Through verbal questioning, drawing and a vignette, children were repeatedly prompted to engage with two main questions on authenticity in relation to stimulant drugs (stated here in shorthand form): 'Do you feel like you are a different person when you are on/off medication?' and 'Do you feel like the 'you' on/off medication is more/less the real you?' Throughout the interviews, children were encouraged to refuse, contradict or revise the interviewer's formulation of their experiences. Other questions addressed how a child's own views of himself or herself on and off medication correlated with other people's views (peers, teachers, parents).

The majority of children interviewed report that medication has an instrumental impact on behaviour, but does not make them feel that they are a different person.

INT: Would you say that you feel like you're a different person when you take your tablets?

I'm the same person either way [on or off medication]. Both of them are me. Medication slows my brain down and makes good ideas stay longer. (Joe, US, age 10)

INT: Some people think taking medication might turn you into a different person. What do you think about that?

With medication it's not that you're a different person; you're still the same person, but you just act a little better. Medication will help you control yourself. (Angie, US, age 11)

INT: Would you say that you're the same person when you're taking your medication, or are you a different person - or is that just a silly question?

I'm a bit, I'm a bit of both. Like I am a bit the same person I always are [on medication]. It's just, I act a bit different, but I'm, I actually are always, I am always the same person. (Laurence, UK, age 10)

Angie and Laurence make a distinction between the effects of medication on the person, and the effects of medication on behaviour. This distinction is frequently reflected in parents' remarks: I tell him [child] that even if I'm unhappy with his behaviour, I still love him. Or: I'm glad to know it's a problem with his behaviour and that he's not a naughty child. Children do not simply parrot their parents' beliefs about this person- behaviour distinction. They also defuse an assumption, contained in many critical analyses, about the power of stimulant medications: Children claim that while stimulants are helpful, they are not sufficiently powerful to engender radical change in the person or in behaviour.

The medication doesn't really change who I am completely. I still have problems even when I'm on the medication. (Flora, US, age 12)

... I'm always hyper even when I'm on my tablets ... [On medication] I'm mostly good, but I still have moods... I'm still am what I am. (Don, UK, age 11)

When I'm on my medication I'm still [myself]. It's just that I'm a bit more and a bit less of some of the things ... The medication can't just take you over and then control you and what you do... It can't make you a Ben or a Tom or someone else with a 3-letter name. (Davy, UK, age 14)

Similarly, when asked directly whether the self on or off medication is experienced as a more real self, children frequently resist the binary option presented by the question, in favour of articulating a continuous sense of self:

INT: Who would you say is the real Justin? The Justin on medication, or the Justin off medication. Or, would you say actually, you know, I don't agree that I'm real one way, or not real the other way?

Yeah, I don't agree with that. I'm just ... there's only a slight change in my personality, but I'm still the same person. (Justin, US, age 14)

This experience of variations within the self is not associated with distress in most children we interviewed; it is not reported as an experience of self-alienation. Even when children consider that their real self may be more the self off medication, they do not see this as a reason to stop taking medication:

The tablets are making me into, like, a person who has like, two heads. Have you ever seen, um ... the Nutty Professor. The first one where he keeps changing into Buddy and the Professor. He wants to be thin and slim ... he wants to be perfect ... So I feel like him; I feel like, I feel like I'm the Nutty Professor and when I'm on my tablets, I feel like Buddy - not perfect, but you know ...

INT: So, how does it feel to be these two people?

Well, I've got used to it actually, so I know what to expect and what to do ...

INT: So it doesn't feel bad to you, to have to deal with both of these people inside you?

No. (Zach, UK, age 13)

If the authentic self is represented by an inner voice, then both Buddy and the Nutty Professor whisper in Zach's ear. ${ }^{12}$ Zach experiences no obvious authenticity-conflict in relation to these voices; they are different parts of him that coexist within the whole. Alexandre Erler makes the point that proponents of the inner voice authenticity argument do not define what the authentic voice is when there are 'multiple yet incompatible candidates'. ${ }^{21}$ Zach suggests that this definitional effort may need to account for the possibility that authenticity can include multiplicity and incompatibility.

This textured account of the self is even more interesting when considered in the context of accounts that parents gave verbally, with their children present, and in writing. When 
reporting on the impact of medication, parents tend to emphasise both binary change in a child and self-discovery, with statements like: He's like a different child; or, Finally he can know himself as a successful child; or, She's so much happier with herself now. In this study, six children consistently echoed such accounts. All six children were 9 years old (the youngest children we interviewed), representing $40 \%$ of 9 -year-olds with experience of stimulants in the sample. Their common age suggests that characteristics of the developmental stage, for example, concrete reasoning and a desire to please adults, may increase the risk that stimulant drug treatment (at least rhetorically) 'bypasses' moral struggle. When asked directly about differences in themselves on and off medication, this group of children delivers binary self-evaluations:

[With the medicine] I ain't being naughty no more... I'm not doing anything to other people now. [The medicine] makes me good again. [If I didn't take it] I'd probably get into lots of trouble. [Tablets] have changed my life ... like, stopped making me bad ... and pushing people over ... and starting fights. (Cecil, UK, age 9)

Cecil's mother tells us that Cecil has been on medication since age 4 , and that medication has made all the difference.

The majority of children in this study express a more subtle idea: stimulant drugs put them in the position of being able to choose between versions of themselves depending on what the situation calls for. Their accounts suggest that they value a version of authenticity that is less about self-discovery and more about the potential for self-actualisation via the development of self-control:

\begin{abstract}
I know when [the medication] is working because I'm more quieter. I can sit still longer. And I don't have to fiddle about so much. I prefer myself like, in the middle. Like if you've got $A D H D$, you would prefer yourself in the middle, because you'll know when you're about to go into, when you're going to be hyper and when you can control yourself a lot more. And that's why I think I should be more in the middle a lot. (Timothy, UK, age 11)
\end{abstract}

[With medication] I'm in the middle ... it's kind of like me looking to the angel and me looking to the hell. Angel, hell; angel, hell ... (Tristan, UK, age 9)

It is notable that Timothy and Tristan speak to the very concerns that Fukuyama ${ }^{6}$ and other bioethicists have raised: the importance of genuine moral decision-making to the development of moral agency. However, in these children's reports, stimulant drugs enable, rather than threaten, moral reasoning in face of conflicting impulses. In Tristan's words, he can choose 'the angel' or he can choose 'hell'. Children value this position of choice. Arguably, it is the repeated experience of sitting 'in the middle' and choosing the right action that supports the development of moral responsibility and understanding of oneself as a moral agent. Moreover, as Glenn points out below, it is the child who makes the decision about how to act, not the medication:

If you're like driving in a car, and like, there's two different ways, and you usually always go this way ... and then one day you want to go the other way, but ... the ADHD acts as like a blocker, so you can't... It [the medicine] opens the blocker so that you can go [the right] way. But you still have the choice of going the wrong way ... It's harder [without medication], that's what's the truth. But it's not like [on medication] you're a robot ... (Glenn, US, age 10)
Such accounts suggest that the view represented by Kureishi ${ }^{1}$ and others, that children are 'stupefied' by Ritalin, or turned into mindless, obedient zombies, unfairly characterises a majority of children's capacities for self-reflection and moral awareness while taking medication and disregards the high value children place on their capacity for moral agency, which many experience as being enabled by medication.

\section{Objections}

I have shown that although children are able to engage with concerns about authenticity, the majority does not perceive stimulant drugs to be a threat to authenticity. There are several objections to consider. The first is that children are simply too young to have substantive concerns about identity or to recognise a threat to authenticity. A second point is about method: children might not respond to direct questions about threats to authenticity, but would report concerns about authenticity more indirectly.

These objections can be considered together. A small number (approximately $8 \%$ ) of children in this study do indirectly articulate threats to authenticity, almost exclusively in relation to an experience of medication 'side effects'. Notably, children do not articulate the identity confusion (which is the true me?) found in some adult accounts of psychotropic medication. ${ }^{22}$ Rather they are, in retrospect, clear that on medication they experienced intolerable self-alienation:

\section{I didn't feel like myself when I was taking the medication}

I just felt suckish all the time

I was too quiet; it wasn't me

\section{My friends said I wasn't myself; I didn't laugh.}

Because the threat to authenticity here is viewed as a side effect, rather than as an intrinsic quality of stimulant drug treatment, children do not necessarily reject medication completely. About a third of the children who reported this side effect had found, or were hoping to find, a medication that did not make them feel this way.

On the basis of these accounts, it is evident that children are able to report and to resist threats to authenticity. In younger children, parental and caregiver perspectives are likely to be an important influence on the ability to recognise such threats. As children get older, the peer environment becomes more of a factor in authenticity accounts:

Without medication it's hard to listen to that little voice in my head [telling me not to do things]. [With medication] I think twice before I speak and do things... Like, when I'm on medication I'm more calm and people seem to like being around me, but when I'm not, I'm more fun to be around ... But the medication also makes me depressed ... I haven't found a medication that's made me feel myself but like, still focus and like, most medications I've had, my friends kind of got bored with me ... (Myra, US, age 13 , taking a break from medication)

Finally, we should consider the objection that those children who do not perceive stimulants as a relevant threat to authenticity are wrong. On the self-creation account, the argument would go something like this: when children say that medication puts them in the middle as decision-making agents, they are in fact identifying the starting point of a moral journey of selfcreation. This journey could involve a threat to authenticity if the child's path were not free or just. As we have seen, the use of stimulants in children can be framed as an oppressive project 
of socialisation. To properly evaluate this claim, we need to know more about what it is that medication is perceived to be doing as part of children's self-creative journeys, and what form (s) of agency are valued and promoted in children through the use of stimulant drugs.

\section{Good conduct and good performance}

The first task is to describe something of the social contexts that children inhabit. As described in the methods section, the VOICES study used the concept of the ecological niche to analyse the complex and subtle dynamics between a child and the surrounding environment, on a micro and a macro level. Two niches were discovered in the VOICES study. These niches give rise to distinctive experiences with ADHD diagnosis and stimulant drug treatments. In a performance niche, children's cognitive achievements are strongly emphasised. ADHD is viewed as a disorder of academic performance, and children articulate the effects of stimulant drugs in relation to classroom behaviour, school work, intelligence and academic achievements. In a conduct niche, children's social behaviours and social hierarchies are a dominant preoccupation among children and adults, and academic achievement by children does not outrank other obligations. ADHD is viewed as a disorder of anger and aggression, and stimulant drugs are seen by children to improve emotional self-control, aggressive behaviours and moral decision-making. (These niches are drawn sharply here for illustrative purposes, and are both softer and less distinct in reality.) In this study, the niches were associated with national differences: among US children we interviewed, the performance niche was the modal niche environment; and among UK children we interviewed, the conduct niche was the modal niche environment (see figures 1 and 2). ${ }^{\mathrm{i}}$

In a conduct niche, children emphasise the improvements in their social behaviours with medication, particularly in relation to their capacity to make good decisions:

It [stimulant medication] makes me like, helps me behave better but it don't make you behave better it can only help you, but it can make, help make better decisions for you. (Roger, UK, age 13)

In children who experience school environments where physical and verbal aggression is a common experience, 'better decisions' are often linked to better impulse control in aggressive situations. ${ }^{19}$ In these contexts, medication frequently has both an instrumental, and an overtly moral role, not because it improves children's behaviour directly, but because it enables children to assess whether a particular situation justifies an aggressive response. As we saw earlier, the most important function of medication is not to 'tell' a child what the right action is, but to enable a child to make a mental space for deliberation. It is this capacity for reasoning, even in face of peer aggression, that constitutes what we might call good character:

Um, being good and bad is to do with thinking about your actions. Um, and I think if you're bad, then you don't really think about your actions very much ... (Conrad, UK, age 13)

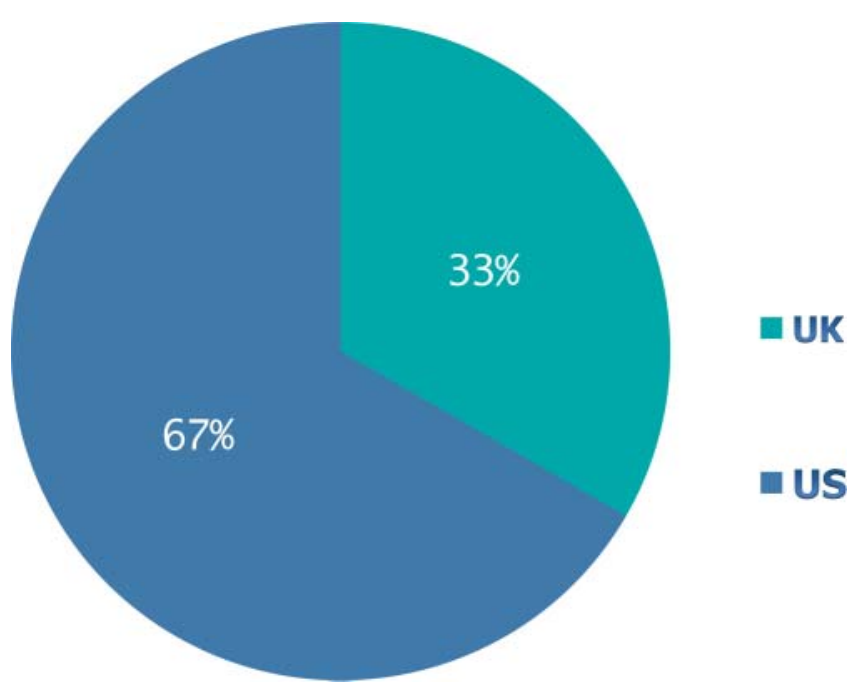

Figure 1 The proportion of children who report that stimulants help to improve classroom and academic performance. This figure is only reproduced in colour in the online version.

To the extent that medication is here engaged in performing moral social work, it operates within a complex social system of obligations and hierarchies. Unsurprisingly, then, conduct niche children occasionally refer to medication in emotional terms: it is like a friend. As a friend, medication reminds a child to weigh the aggressive act against its probable consequences. Roger explains:

Helping me, means like just saying like, say if my mate was going to fight, or like if I was going to fight, my mate saying, you know you don't want to do it because you'll probably get arrested or something. It's like [the medication] is like saying, you're not going to fight and then like, them [friends] holding me back or something ... So [medication] is like a friend but not it.

If in a conduct niche, medication does overt moral work, in the performance niche, the work of medication is, overtly, more pragmatic. Here, children are more likely to view the effects of stimulant drug treatments in relation to school work:

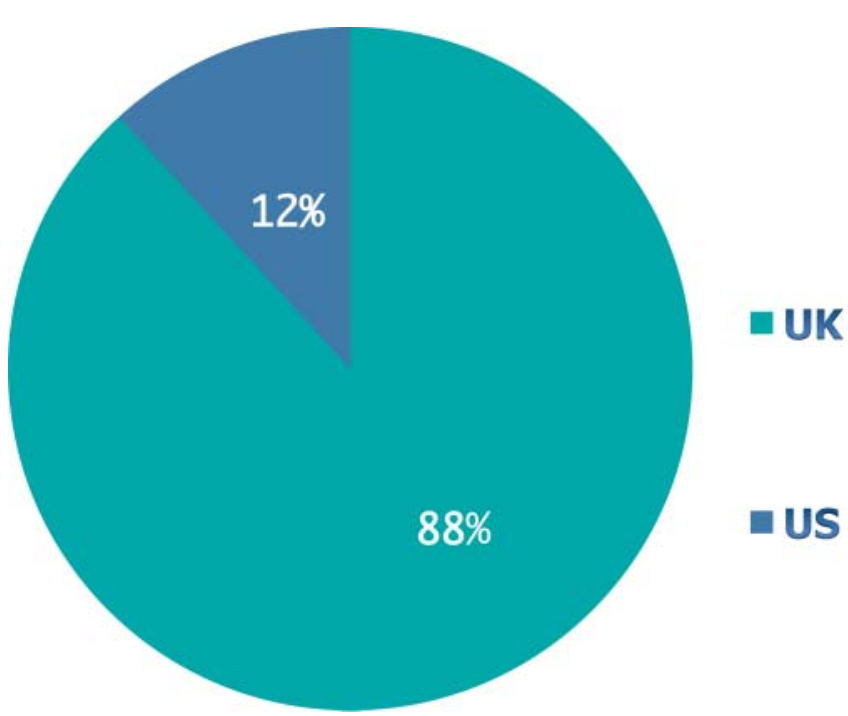

Figure 2 The proportion of children who report that stimulants help to manage anger and aggressive behaviours. This figure is only reproduced in colour in the online version. social class. However, given that this is a small, non-random sample, no general conclusions about national characteristics should be drawn from this data. Moreover, individual differences not discussed here are important to consider. 
I think I might actually go back on medication because I'm, like, failing math right now ... (Myra, US, age 13, taking a break from medication)

If I'm in school like yeah because it [medication] helps me focus on something ... and it helps me like, okay, if I'm doing a math problem like do this and then do this and then do this. (Adrian, US, age 11)

Parents and children frequently provide an instrumental rationale for why many US children stop using medication during weekends and school holidays: stimulant drug treatment is expressly for school. As Adrian observes:

[In the summer I don't take the pill] because I can just relax there because I ride my bike every day. I'm always active, what I want to do. So I'm okay in the summer but not in school time.

Performance niche children do occasionally make a direct association between cognitive achievement and moral behaviourthat is, with doing the right thing-thereby illustrating that despite the instrumentality associated with stimulant drugs, the treatments are doing work in a moral dimension:

INT: What makes a person good?

Um, me being smart. (Vaughn, US, age 10)

Valued cognitive capacities, such as intelligence and attention, constitute the right actions:

[With medication] I like, I finish my homework earlier and I don't get in trouble a lot anymore. I pay attention a lot more ... It feels great ... The medication, it like, changes, like, what you're doing and, like what you're thinking. Like all of a sudden, like, you know that you're not doing what the teacher told you to do, so then it just changes what, so then, so then, you can do the right thing what the teacher told you, so you can pay attention more better. (Camilla, US, age 10)

It is also clear from our interviews that academic achievement meets obligations children feel to their families.

I got two As and a B on my report card and my mom freaked out, she was so happy. (Oscar, US, age 11)

INT: Tell me about a time when you weren't very happy with how you behaved.

Um I got my name on a board, and I got Fs on my report card, and my mom was really mad. And she told me that you need to do better, and she, and I was really happy this year, that it's really good. But last year, I wasn't paying attention. (Rose, US, age 11)

Many children, and older children in particular, are aware that they live in conditions in which these obligations inform standards and expectations of behaviour. For the most part, they note these conditions with a degree of equanimity. Adrian goes on to say:

The pill kind of like helps the mothers and the fathers and everybody else live peacefully... And moms won't be like frustrated because they have to do more work or something.

We see that in this niche, children view medication as a tool that enables them to meet obligations to themselves and to others; and these obligations include cognitive self-care, a commitment to invest in and to cultivate the capacity to succeed in cognitive activities.

\section{Niche norms and moral capacities}

We are now in a better position to address the challenge to children's lack of concern about a threat to authenticity posed by stimulant drugs. It seems clear that children associate stimulant drug treatment with improvements in their capacities to meet the normative expectations of their respective niches. Children value the promotion of these capacities, and many show awareness of their normative dimensions. Nevertheless, the argument that children's self-creative path is not free, in that medication is used as a norming tool, or as a means to make children more docile in face of possibly oppressive academic and behavioural expectations fostered in certain niches, seems plausible. On the self-creation account, acquiescence to normative niche expectations, through stimulant drug use, can be said to elevate the risk of a threat to authenticity. Such acquiescence on the part of children and their families also raises the risk of other harms, such as medicalisation or the coercive use of drugs. The force of these threats is underscored by the fact that the pharmaceutical industry plays a powerfully prescriptive part in popularising 'normal' child behaviours and emotions, as well as, through their direct to consumer advertising, in promoting models of achievement and success, happy families and good parenting (especially good mothering). ${ }^{23} 24$

Nevertheless, if under certain conditions stimulant drugs elevate the risk of a threat to authenticity, this still does not mean that stimulant drug treatments regularly violate authenticity. All children are subject to socialising processes throughout development, during which they must continually meet normative expectations. Arguably not all of these processes constitute actual threats to authenticity. It is critically important that children have the capacity to protest norms, and in the first part of this article we saw that stimulants both allow and even promote decision-making capacity and moral agency in children. If stimulants do not generally undermine moral capacities, then we are faced with two difficult challenges: First, are the norms of performance and conduct to which children are subjected valuable? If we think these norms are overvalued, then the solution is not to deny children the possibility of better meeting normative expectations. Rather, we ought to encourage non-accusatory reflection on the values embodied in these norms. Second, if stimulants pose potential harms and they have potential benefits on the journey to an authentic self, then how can we get better at maximising the benefits, and at recognising, describing and intervening in bad conditions, in which the use of stimulant drugs undermines children's moral or self-creative capacities?

A partial response to these challenges emerges when we acknowledge children's evident desire and capacities for agency. If a majority of children are not victims of stimulant drugs, then they can be engaged to help uncover threats to agency or to authenticity, and they can be constructively supported to protest normative expectations and the accompanying tools, as appropriate. Children also need to be able to openly discuss the value of medication in relation to their capacity for moral decisionmaking and their capacities to meet standards of behaviour demanded of them in a given ecological niche.

\section{A role for medical professionals}

On whom is the obligation to support children in these ways conferred? The demand to engage children in non-judgmental, reflective, supportive discussion about stimulant drug use involves parents, teachers and other caregivers, but it is essentially part of a clinical ethics. As gatekeepers to stimulant drug treatments, medical professionals should take on the dual 
commitments of inviting a child to speak and of reflective listening, as part of an ethically informed clinical practice. This should be a relational and collaborative stance, rather than an authoritarian one: a genuine invitation to a child to speak recognises the child as (at least a potential) agent, capable of reason and reflection and worthy of dignity and respect. A pharmacological treatment approach can include this kind of broader therapeutic orientation to the patient, where the point is to identify and manage the problems a child is experiencing, rather than just to diagnose and treat symptoms. Such an orientation acknowledges the child (and indeed the physician) as actors in a social world that gives moral weight to children's cognitive and behavioural capacities.

Such a role places an enormous demand on medical professionals, when time, training and resources to talk, listen and build a trusting relationship with child patients are scarce. ${ }^{25}$ Children in the VOICES study routinely report that they have little contact with medical professionals:

I've only just started going to the ADHD clinic, but I haven't actually been to it properly, like, I've seen the doctor and he's talked about [ADHD] and I get weighed ... But ... they don't, they'll just say like, parts of what it is but then, like, they'll stop, so they will only say some of it and then, like change the subject. (Roger, UK, age 13)

INT: What does the medication do? Why are you taking it?

I don't know. To make me be good.

INT: Do you want to keep taking it ... Why?

Cos the doctor told me to.

INT: Do you like your doctor?

I don't know who is my doctor. (Sebastian, US, age 10)

Only a handful of children in the VOICES study view medical professionals as a resource to talk to about difficult issues in relation to their diagnosis or treatment. The lack of relationship between medical professionals and child patients, and the lack of substantive discussion of normative issues in the clinical realm and elsewhere arguably contribute to elevating the risk of ethical harms of stimulant drug treatment. Therefore the lack of resources to build such a relationship is a clinical, societal and ethical concern that warrants interventions at the level of paediatric mental health policy, clinical ethics and medical education.

\section{CONCLUSIONS}

We have seen that children generally have positive responses to stimulant drug treatments. They primarily see stimulants as supporting their capacity for moral agency. Niche conditions influence how children express their experiences with stimulant drug treatments, and how they conceive the value and work of the drugs. Most children in this study did not experience stimulant drug treatment as a threat to authenticity, but such a threat is a potential risk to children. It is possible to identify concrete steps to minimise the risks and to maximise the benefits of stimulant drug treatment: I have argued that medical professionals should take a lead in building on children's evident capacity for critical reflection on niche conditions, moral behaviour and the norming work of stimulant drugs, as part of a commitment to children's flourishing.

How do the perspectives of children move the Ritalin debates on? Let us say that after reading this article, a sceptic is not convinced that stimulant drugs can support children's flourishing. Plausible justifications for such a position certainly remain. However, the sceptic will now need to acknowledge that the debate cannot accurately be framed as one between absolute goods and absolute harms; for example, children's liberties versus Ritalin. Children's perspectives show us, at the least, that it is possible to make important claims for stimulant drugs as a good. ${ }^{\text {ii }}$ This acknowledgement changes the nature of the debate: if the sceptic wants to maintain his or her position, he or she ought to do so with respect for the aspirational human agents involved, and for the complexity of the problem, and not in wilful ignorance. Perhaps the sceptic will be more inclined to have empathy with those who might suffer as a consequence of his or her position, as indeed, many children and families who are subjected to the debate in its traditional divisive form, suffer.

I am hopeful that if we can change the nature of the debate, by framing the case of stimulant drugs as a problem of tensions among contending goods, we will get better and farther in our arguments, generate more insightful public discourse, and ultimately enable more relevant and more reasonable evaluations of the impact of stimulant drug treatments on children's flourishing. More generally, as the arsenal of interventions into children's cognition and behaviour grows, balanced, deliberative and empirically grounded analyses should enable more accurate descriptions of bad conditions, in which children's vulnerability is increased by interventions. This accuracy should translate into identification of relevant means by which the social and moral development of children in general-but particularly those who are at risk-is promoted.

Acknowledgements Thanks to the VOICES study research assistants, our clinical collaborators and the UK MHRN. Huge gratitude to the children, parents, relatives and doctors who participated in the study. Special thanks to Hanna Pickard and the OCN reading group for insightful comments and careful reading of drafts. Thanks also to Brocher meeting participants for helpful discussions on authenticity. VOICES is funded by a Wellcome Trust university award no. 08029.

\section{Competing interests None.}

Provenance and peer review Not commissioned; externally peer reviewed.

Open Access This is an Open Access article distributed in accordance with the Creative Commons Attribution Non Commercial (CC BY-NC 3.0) license, which permits others to distribute, remix, adapt, build upon this work non-commercially, and license their derivative works on different terms, provided the original work is properly cited and the use is non-commercial. See: http://creativecommons.org/ licenses/by-nc/3.0/

\section{REFERENCES}

1 Kureishi H. The art of distraction. The New York Times 18 Feb 2012.

2 Vasconcelos MM, Werner J Jr, Malheiros AF. Attention deficit hyperactivity disorder prevalence in an inner city elementary school. Arq Neuropsiquiatr 2009;61:67-73.

3 Polanczyk G, de Lima MS, Horta BL, et al. The worldwide prevalence of ADHD: a systematic review and metaregression analysis. Am J Psychiatry 2007;164:942-8.

4 Zito JM, Safer DJ, Lolkje TW, et al. A three-country comparison of psychotropic medication prevalence in youth. Child Adolesc Psychiatry Ment Health 2008;2:26. Published Online First: 25 September 2008. doi: 10.1186/1753-2000-2-26

5 Scheffler RM, Hinshaw SP, Modrek S, et al. The global market for ADHD medications. Health Aff 2007;26:450-7.

6 Fukuyama F. Our posthuman future. London: Picador, 2002.

7 President's Council on Bioethics. Beyond therapy: biotechnology and the pursuit of happiness. Washington, DC: Dana Press, 2003.

8 Conrad P. Medicalization and social control. Annual Rev Sociol 1992;18:209-32.

9 Horwitz A. Creating mental illness. Chicago: Chicago University Press, 2002.

10 Shonkoff JP, Siegel BS, Dobbins MI, et al. Early childhood adversity, toxic stress and the role of the pediatrician: translating developmental science into lifelong health. Published on-line December 26, 2011. doi: 10.1542/peds.2011-2662

11 Foresight Mental Capital and Wellbeing Project. Final project report. London, UK: The Government Office for Science, 2008.

12 Levy N. Enhancing authenticity. J App/ Philos 2011;28:308-18. Published Online First: 7 June 2011. doi: 10.1111/j.1468-5930.2011.00532.x

${ }^{i i}$ My thinking here is indebted to Charles Taylor's arguments (as I understand them), primarily in Sources of the Self: The Making of the Modern Identity. Cambridge, UK: CUP, 1992. 
13 Kramer P. Listening to prozac. New York: Penguin Books, 1993.

14 DeGrazia D. Human identity and bioethics. London: CUP, 2005.

15 Parens E. Authenticity and ambivalence: Towards understanding the enhancement debate. Hastings Cent Rep 2005;35:34-41.

16 Elliott C. The tyranny of happiness: ethics and cosmetic psychopharmacology. In: Parens E ed. Enhancing human traits: ethical and social implications. Washington, DC: Georgetown University Press, 1993.

17 Conrad P. The medicalization of society. Baltimore, MD: Johns Hopkins University Press, 2007.

18 Bronfenbrenner U. The ecology of human development. Cambridge, MA: Harvard University Press, 1979.

19 Singh I. A disorder of anger and aggression: children's perspectives on ADHD in the UK. Soc Sci Med 2011;73:889-96.
20 Singh I. Will the 'real boy' please behave: dosing dilemmas for parents of boys with ADHD. Am J Bioeth 2005;5:34-47.

21 Erler A. One man's authenticity is another man's betrayal: a reply to Levy. J App/ Philos 2012;29:257-65.

22 Karp DA. Is it me or my meds?: Living with anti-depressants. Cambridge, MA: Harvard University Press, 2006.

23 Elliott C. Better than well: American medicine meets the American dream. New York: Norton, 2003.

24 Singh I. Not just naughty: 50 years of stimulant drug advertising. In: Toon A, Watkins E eds. Medicating modern America. New York: New York University Press, 2007.

25 Luhrmann TM. Of Two minds: an anthropologist looks at American psychiatry. New York: Vintage, 2000. 